\title{
A Simple Decision Market Model
}

\author{
Daniel Grainger, Sizhong Sun, Felecia Watkin-Lui \& Peter Case ${ }^{1}$
}

College of Business, Law \& Governance, James Cook University, Australia

\begin{abstract}
[Abstract]
Economic modeling of decision markets has mainly considered the market scoring rule setup. Literature has made reference to the alternative, joint elicitation type decision market, but no in depth analysis of it appears to have been published. This paper develops a simple decision market model of the joint elicitation type, that provides a specific decision market nomenclature on which to base future analysis.
\end{abstract}

A generally accepted prediction market model is modified, by introducing two additional concepts: "proper information market" and "relevant information". Our work then provides original contributions to the theoretical discourse on information markets, including finding the sufficient and necessary condition for convergence to the best possible prediction. It is shown in our new prediction market model that "all agents express relevant information" is a sufficient and necessary condition for convergence to the direct communication equilibrium in a proper information (prediction) market.

Our new prediction market model is used to formulate a simple decision market model of the joint elicitation market type. It is shown that our decision market will select the best decision if a specific selection and payout rule is defined. Importantly, our decision market model does not need to delay payment of any contracts to the observation of the desired outcome.

Therefore, when dealing with long-term outcome projects, our decision market does not need to be a long running market.

Future work will test for the statistical significance of relevant information (identified as important in our idealized decision market model) in laboratory and real world settings.

\section{[Key Words]: Information market, Decision market, Prediction market, Joint elicitation, Long-term projects.}

\section{[JEL Classification]: D83, G14}

\footnotetext{
${ }^{1}$ In addition to holding a chair in management and organization studies at JCU, Peter Case is also professor of organization studies at the Faculty of Business \& Law, University of the West of England, UK.
} 


\section{Introduction}

This paper reviews and extends the theoretical models of decision markets ${ }^{2}$. A generally accepted prediction market model is modified and a sufficient and necessary condition for it to provide a best possible prediction of future events is derived. This new prediction market model is used to build a simple decision market model that will always select the best possible decision for anyone using it as a decision support tool.

Our work provides three original contributions to the theoretical discourse on information markets: (1) formulating a prediction market model with a sufficient and necessary condition for a well-functioning prediction market, (2) creating a simple decision market model with a deterministic decision selection rule (as opposed to a mixed strategy decision selection rule required in a prominent decision market type discussed below) and (3) showing that our decision market does not need to operate for as long as the projects it analyses (and hence short term decision markets can assist in decision-making of long term projects).

Our results assume idealized rational, risk-neutral and myopic traders populate information market models. This is not only done because it is the typical approach taken throughout literature when modeling such settings, but also because of the significant advantage gained. Just as the law of gravity assumes no air resistance, our information markets assume no strategic or risk-averse traders exist. These idealized assumptions expedite the revelation of key insights for both gravity and information markets otherwise lost in intractable problems. That said, it is useful to test these insights within settings that are consistent with real world dynamics. This will be done in future work.

Our main theoretical contribution to the prediction market literature, made easy by our choice of mathematical nomenclature, is placed in Appendix 1. The body of this paper then provides a narrative account of the 'big ideas' behind our mathematical formalism. This is done in an attempt to maximize the accessibility of our work to the broader readership; it also offers transparency and completeness by including the details of our work in the appendix. Section 2 reviews the related literature concerning theoretical information markets with an emphasis on decision markets. Section 3 reviews a generally accepted prediction market model that is modified to formulate the key results of this paper. Section 4 introduces the concept of "proper market price" underpinning the definition of "proper information market". The notion of "relevant information" is also introduced. Theorems 1 and 2 find that "all agents express relevant information" is a sufficient and necessary condition for convergence to the best possible prediction in a proper information (prediction) market. Our new prediction market model is extended in theorem 3 to a context with multiple stocks. With the multiple stocks context in hand our simple decision market model is developed via theorems 4 to 7. Section 5 discusses our findings and section 6 concludes with suggested future research.

\section{Related Work}

Information markets continue to be of interest to researchers, with the number of articles published per year steadily increasing since 1990 (Tziralis and Tatsiopoulos, 2012). Whilst there exists much experimental and real world evidence of the effectiveness of information markets, there was envisaged a need to provide a comprehensive theoretical foundation to reveal why they worked so effectively (Chen et al., 2006).

The following review of related work considers the early theoretical work on information markets. This leads naturally to the dominant Boolean models of prediction markets and the important issue of designing price formation mechanisms that are consistent with incumbent

\footnotetext{
2 Decision markets are a generalization of financial markets whereby random variable events are listed as assets and asset prices are used to derive conditional probabilities used in decisionmaking.
} 
agent behavior. The current theoretical formulations of decision markets are surveyed and an impetus for our work, rigorously exploring joint elicitation decision markets, is revealed.

\subsection{Early theoretical work on information markets}

The seminal work of Aumann (1976) on knowledge and information arguably provides a pioneering formalism for information markets. Aumann defined an event as common knowledge if two agents are present at that event and they see each other present at that event (Aumann, 1976). This definition, made more rigorous by an associated set theoretic formalism, led to the analysis of multiple agents with private information trading in a marketplace. McKelvey and Page discovered that when a stochastically regular aggregate statistic is common knowledge, an equilibrium is reached after finite rounds of announcements and the posterior probabilities of all agents become identical (McKelvey and Page, 1986). These information and equilibrium ideas form the theoretical foundations of prediction (information) markets and decision (information) markets that reach the 'best prediction' equilibrium and 'best decision' equilibrium.

\subsection{Boolean finite state space models of prediction markets}

Theoretical prediction markets have been modeled as computational processes that aggregate and process distributed bits of information and hence the natural appeal to their representation as Boolean finite state space machines (Gao and Chen, 2010)

In Boolean finite state space prediction market models, with no aggregate uncertainty of information, the equilibrium price will be the correct forecast if the function denoting the prediction of interest can be represented as a weighted threshold function (Feigenbaum et al., 2003). If however, aggregate uncertainty is allowed into the model, then the market does not in general converge to the correct forecast; rather it can only ever approach what has been termed the best possible prediction (Chen et al., 2004).

A novel approach taken to further understand the complex nature of market information is the application of information theory concepts e.g. Shannon's entropy in the form of Talagrand's inequality applied to markets (Ronen and Wahrmann, 2005). Whilst applicable, and potentially the nucleus of market information, the entropy of an information market is arguably difficult to interpret.

In contrast, the complexities associated with framing market information in terms of information signals and entropy may be wholly sidestepped should simplifying nice conditions hold. For example, an important simplifying sufficient condition that has been proven for a prediction market model with aggregate uncertainty is if there is an independent and identical distribution (IID) of agent information, then the information market will converge to its best possible prediction (called the direct communication equilibrium and simply denoted DCE) (Chen et al., 2004). Importantly, the IID assumption simplifies the model setting so that other interesting features of prediction markets may be investigated.

\subsection{Price formation mechanisms of prediction markets}

A key feature of information market models is the price formation mechanism. Basically, research has considered two alternative setups. The first is simply assuming a double-sided auction exists at which buyers and sellers meet to bid and trade (as is the case in the stock market). The potential problem with this set-up is the risk of illiquidity in the market i.e. when no trade takes place for any one of the stocks. This situation potentially causes divergence from the ideal market price incorporating all market information. But, more alarmingly, there exists a logical certainty that no trade can ever take place if we only allow rational players into a zero sum market game (Milgrom and Stokey, 1982). In contrast, the other price formation approach is to introduce a market maker that guarantees trading takes place and thus mitigates the illiquidity and mispricing risk; albeit at a financial loss to the market maker (Hanson, 2003). 


\subsubsection{Double-sided auction mechanism}

Although it is utilized in the real world, in the theoretical world the double-sided auction does not incentivize rational agents to reveal private information and so a liquidity problem arises in theoretical prediction markets as a direct result of Milgrom's no trade theorem (Chen et al., 2010). To overcome this significant theoretical problem extra conditions were imposed upon theoretical information market models, ranging from noisy traders to forced trading. The underlying idea was either to create the potential for a rational trader to gain and therefore incentivize their participation, or simply create the law that traders must always bid. By participating in the market, noisy traders (who play a comparatively suboptimal strategy) create an opportunity for a rational player to gain by participating in the market. In one sense, the automatic market makers play a suboptimal strategy thereby incentivizing rational players to enter the market game and gain from the automatic market maker losses. Alternatively, forced trading such as that espoused in the prediction market of Chen (2004) directly removes the no-trade possibility. For example, a forced trading rule such as "each round traders must place an order quantity $q$ between 0 and 100 and pay $\frac{q}{2}$ cents for it" guarantees trader participation, and is incentive compatible with the rational, risk neutral and myopic traders.

Game theory provides a useful means to analyze price formation in various double-sided auction settings (Shapley and Shubik, 1977). For example, in the Vickrey second price auction, in contrast to English and Dutch-style auctions, the dominant strategy is for agents to bid truthfully. As such we have a model that captures the complexities of strategic bidding as well as incentivizing players to bid truthfully. However, Vickrey double-sided auctions assume risk neutral strategic agents. For risk averse agents, truth telling is no longer a dominant strategy in a Vickrey auction and information uncertainty exacerbates this even further whereby a market price forms that is not based on true trader information (Sandholm, 1996).

\subsubsection{Automatic Market Maker: Market scoring rule mechanism}

Market scoring rules were originally designed to combine the benefits of scoring rules with the advantages of market efficient aggregation of information (Hanson, 2002). The benefits of a market maker with an appropriate market-scoring rule have become prominently advocated in existing literature. For example, Hanson's logarithmic market scoring rule (LMSR) market maker reduces the risk of thin illiquid markets to a bounded financial loss to the market maker when assuming rational, risk-neutral myopic agents trade within the marketplace (Hanson, 2012). The financial loss under these assumptions can be certainly bounded through the parameters of the LMSR given that the entropy of information distribution is directly related to the worst case loss (Hanson, 2003).

\subsection{Strategic bidding in models}

Information market models usually assume rational, risk-neutral and myopic incentive compatible traders and not strategic traders. Strategic behaviors such as reticence and bluffing have been explored with particular emphasis on aligning truthful betting with rational behavior, but this still anticipates a detailed development of non-myopic models (Chen et al., 2007). Of significant interest is the creation of incentives that encourage truthful betting amongst non-myopic agents (Chen et al., 2010). The need for a non-myopic agent model has been avoided altogether in some theoretical models that argue only myopic agent behavior remains in a market where the number of traders is large; since in such a market there will be negligible impact of strategic behavior on price and the cost of complicated strategic reasoning outweighs these negligible benefits (Chen et al., 2006).

\subsection{Decision markets}

Decision markets, also called conditional prediction markets, have been defined as an instrument to aggregate market information to reveal the best decision (Berg and Rietz, 
2003). A real world embodiment of a decision market, which was considered the only realworld example of a large conditional prediction market, was "The 1996 Presidential Election Iowa Electronic Market" (Berg and Rietz, 2003). Therein the conditional probability of the success of a party given a particular candidate was able to be expressed and could arguably be used for decision making as to which candidate maximized success. Othman \& Sandholm (2010a) consider this "prediction market - decision market" link further and suggest that whilst current corporate prediction markets have been designed as "cameras" (that capture the prediction of the future outcome), they are in fact "engines" (where conditional predictions actually alter the decisions of the firm as it attempts to safeguard or avoid the predicted future outcome).

Theoretical models for decision markets still need to resolve a number of outstanding issues including but not limited to perverse incentives and inelegant rules (Pennock and Sami, 2007). The two theoretical decision markets that motivate our paper are now reviewed.

\subsubsection{Scoring rule decision markets}

One theoretical formulation of a decision market has simply extended the market scoring rule prediction market model by incorporating into it a decision rule (Chen and Kash, 2011). These scoring rule decision markets are arguably the current popular form of theoretical decision market models. However, in this decision market formulation, a mixed strategy decision rule is required (Chen et al., 2014). Unfortunately, an inconsistency exists whereby the decision maker implements a mixed strategy and possibly selects a suboptimal decision despite knowing it as such (Chen et al., 2011).

\subsubsection{Joint elicitation decision markets}

A less popularized theoretical implementation of decision markets is the "joint elicitation market" which is defined as a market which trades contracts for "actions" and contracts for "outcomes and actions" and then simply uses the respective contract prices to calculate conditional probabilities (Othman and Sandholm, 2010). However, a potential problem of the joint elicitation market arises when an agent, knowing the exact moment that the final round is to occur, makes a strategic purchase of any arbitrary action whatsoever to achieve profit (Othman and Sandholm, 2010). The joint elicitation decision market is briefly mentioned in literature but no analysis of depth similar to the market scoring rule literature appears to have been undertaken. This paper attempts to provide such an analysis. As is the market scoring rule literature, in the first instance, it assumes rational, risk-neutral and myopic traders. This simplifying assumption means that last round strategic play is no longer a problem.

\section{Generally accepted prediction market model}

Chen (2004) introduces, what is referred to by this paper, a generally accepted prediction market model. In Chen's model there exists one stock in the market with multiple agents engaged in multi-round bidding on that stock ${ }^{3}$. Each agent observes one bit of uncertain private information about that stock and market clearing prices from previous rounds that informs their bid. All agents must bid, and bids are aggregated in a market clearing price. At some future point in time the true value of the stock is revealed and an agent will profit depending on their position in the stock.

Chen (2004) takes "an axiomatic approach" and translates the above description into a rigorous formalism akin to the following:

Let $B=\{0,1\}$ and let $s \in B^{N}$ be a vector representing the possible state of the world where $N$ is a positive integer. Let $n$ traders (also called agents) observe a common prior probability

${ }^{3}$ Whilst there is a technical distinction between a stock (unit of ownership) and its contract (enforceable right due to ownership), we use them interchangeably. 
distribution $P(s): B^{N} \rightarrow[0,1]$. One stock (contract) $F$ is traded in this market. $F$ pays money, rewarded at some future point in time, dependent on the value of a Boolean function $f(s): B^{N}$ $\rightarrow B$ whose functional form is common knowledge. Specifically, $F$ pays $\$ 1$ when $f(s)=1$ and $\$ 0$ when $f(s)=0$. Every round all agents submit a bid which is aggregated into a Shapley Shubik market clearing price $p=\frac{\sum b_{i}}{n}$, where $b_{i}$ represents the bid of agent $i$ (Feigenbaum et al., 2003). Agents submit rational risk-neutral myopic bids i.e. the expectation of $f(s)$ conditional on the one bit of information possessed by the agent $\left(x_{i} \in B\right)$ and the information the agent learns from the previous round market price $p$ (and in general, the history of all market prices observed in previous rounds) ${ }^{4}$.

The probability distribution of the information vector of all agents $Q(x \mid s): B^{n} \times B^{N} \rightarrow[0,1]$ is common knowledge where $x \in B^{n}$ represents the $n$ traders' information bits. Notice that in round one arbitrary agent $i$ possesses one bit of information only (namely its own bit $x_{i}$ ) and computes a bid based on that information $b_{i}=E\left[f(s) \mid x_{i}\right]$. All bidders calculate and submit their bids without directly communicating to each other. A $n$ agent market clearing price $p=\frac{\sum b_{i}}{n}$ is then revealed to everyone at the end of round 1 . In contrast, were all agents to directly communicate their private information to one another prior to bidding in round 1 , then equilibrium would be reached at the end of the first round since all agents would bid conditioned on full information i.e. $E[f(s) \mid x]$; we call this equilibrium the direct communication equilibrium (DCE). The DCE is the best possible prediction, since it incorporates all market information.

It can be shown, in this model, that if agent information is independent and identically distributed (IID), then this is a sufficient condition to ensure the information market will converge to the DCE price (Chen et al., 2004). A necessary condition was not identified.

In Chen (2004), a market attaining the DCE price does not also mean that all participating traders are fully informed ${ }^{5}$. In contrast, we are interested in a market that is strictly identical to one in which traders directly communicate private information to one another. Thus our paper states that the DCE is attained only when all traders are fully informed and bid to form the DCE price.

\section{New prediction market model}

This section develops a new prediction market model taking an axiomatic approach. The Chen (2004) model is modified to include two additional concepts, namely, proper information market and relevant information. These concepts are derived from two "proper market price" axioms. It is then shown that "all agents express relevant information" is a sufficient and necessary condition for convergence to the DCE in a proper information (prediction) market. Finally, a payout and selection rule is defined that links multiple prediction markets in order to construct a simple decision market model.

In this section, theorems are stated and the 'big ideas' behind them revealed to facilitate the accessibility of our work to the general reader. Mathematical proofs of theorems are provided in Appendix 1 for completeness and transparency. Where mathematical statements are used in this section (to precisely describe our theoretical model), if they have not already been explained in previous sections, an explanatory narrative accompanies them.

\subsection{Proper market price axioms}

\footnotetext{
${ }^{4}$ Note in the first round of bidding, agents do not observe a previous round market price.

${ }^{5}$ Fully informed means the private information of all other traders is known.
} 
In Chen's model the market price $p$ for $n$ agents at the end of each round is simply calculated as the average of all bids i.e. $p=\frac{\sum b_{i}}{n}$, where $b_{i}$ represents the bid of agent $i$. Agents learn information from market prices. These ideas inspire the following concepts:

- At the start of the market, agents possess private information only. That is, agent $i$ only knows one bit of information $x_{i}$ and as such submits a bid $b_{i}=E\left[f(s) \mid x_{i}\right]$. Notice that the market price is simply $p=\frac{\sum b_{i}}{n}=\frac{\sum E\left[f(s) \mid x_{i}\right]}{n}$. This shall be referred to as the private information stage.

- The market may reach a stage whereby all agents know their private information and the private information of all other agents. When agent $i$ knows all bits of information $x$ they submit bid $b_{i}=E[f(s) \mid x]$. Notice that the market price is simply $p=\frac{\sum b_{i}}{n}=$ $\frac{\sum E[f(s) \mid x]}{n}=\frac{n \times E[f(s) \mid x]}{n}=E[f(s) \mid x]$. This shall be referred to as the full information stage.

- An agent is said to learn a bit of information when the value of that information bit once uncertain becomes known with certainty.

- An agent is said to unlearn a bit of information when the value of that information bit once known with certainty becomes uncertain.

\section{Axioms (proper market price)}

1. There does not exist a market price, resulting from any group or subgroup of the market traders with which an agent bids, whereby that agent learns absolutely no information at the private information stage.

2. There does not exist a market price where an agent unlearns information at the full information stage.

\section{Axiom 1 and the private information stage property}

Axiom 1 is motivated by the notion that a trader will ideally learn something from the first round market price. Axiom 1 introduces the idea that, irrespective of the participating traders, no first round market price is formed where an agent learns not a single piece of new information. As such our new model requires the private information stage property: we are always able to select any $m$ of the $n$ traders (where $m \leq n$ ) to form a market with a first round market price that causes all of the $m$ traders to learn something new.

\section{Axiom 2 and the full information stage property}

Axiom 2 is motivated by the notion that when all traders know all information bit values, the market price cannot cause any trader to unlearn their full information. When all traders are fully informed they know all private information $x$ and will all bid $E[f(s) \mid x]$. As such our new model requires the full information stage property: when all traders know all private information $x$ there cannot exist a market price that causes agent $i$ to become uncertain about (and unlearn) the information bit value $x_{j}$ of agent $j$. Notice that unlearning would occur if agent $i$ sees that a market price $p$ can be attained irrespective of the bit value of $x_{j}$. That is, the market price causes agent $i$ to now consider that either $x_{j}=1$ or $x_{j}=0$ is possible.

If a market price possesses both the "private information stage property" and the "full information stage property" it is said to be a proper market price.

\subsection{Definition (Proper Information Market)}


Our new prediction market model (which is simply the Chen (2004) model modified to require a proper market price) shall be called a proper information market.

\subsection{Definition (Relevant Information)}

The basic idea of relevant information is simply stated as follows. If an agent changes their bid when their information changes, it is said they express relevant information. If an agent does not change their bid when their information changes, it is said they do not express relevant information.

In the first round any agent $i$ will bid $b_{i}=E\left[f(s) \mid x_{i}\right]$ or $b_{i}^{\prime}=E\left[f(s) \mid x_{i}^{\prime}\right]$, when their private information is $x_{i}$ or $x^{\prime}{ }_{i}$ respectively ${ }^{6}$. If $b_{i} \neq b^{\prime}{ }_{i}$ it is said the agent expresses relevant information and that $x_{i}$ is relevant information. Notice that if the first round bid of agent $i$ is known, then the value of their private information bit is able to be inferred. In contrast, if $b_{i}=b^{\prime}{ }_{i}$ then knowing the first round bid of agent $i$ does not allow their private information bit value to be inferred.

This idea may be generalized beyond the first round. For example, in rounds after round 1 an agent may know more than its one bit of private information. Say agent $i$ knows $x_{j}$ as well as $Y$ (with $Y$ representing other information including the agent's one bit of private information). Suppose this agent bids $b_{i}=E\left[f(s) \mid x_{j}, Y\right]$ then should the information bit $x_{j}$ be changed to $x_{j}^{\prime}$ they would instead bid $b_{i}^{\prime}=E\left[f(s) \mid x_{j}^{\prime}, Y\right]$. If $b_{i} \neq b_{i}^{\prime}$ agent $i$ is said to express relevant information and $x_{j}$ is relevant information in this scenario.

For readers desiring a more formal treatment, Lemmas 1.1 and 1.2 in Appendix 1 provide a mathematically rigorous definition of relevant information.

\subsection{Main information market theorems}

The 'big ideas' behind the theorems underpinning our new prediction market and decision market models are now presented. For transparency and completeness, mathematical proofs are provided in 'Appendix 1' for those readers wishing to review our work in greater detail.

\subsubsection{Theorem 1 (Relevant information as sufficient for DCE convergence) \\ "All agents express relevant information" is a sufficient condition for convergence to the direct communication equilibrium (DCE) in a proper information market.}

The condition that "all agents express relevant information in a proper information market" is fundamental to our prediction and decision market models. Appendix 1 contains the associated mathematical proof for theorem 1; showing that when this condition holds a prediction market with one stock converges to the DCE in the second round of trade. The following provides the 'big ideas' associated with theorem 1.

Because "all agents express relevant information", upon knowing the bid of any agent their private information bit value is also known. For example, if agent $i$ has a private information bit value of ' 1 ' it bids $\$ 0.70$ and if it has a private information bit value of ' 0 ' it bids $\$ 0.40$. Now if a different agent was able to determine that agent $i$ bid $\$ 0.70$, they would then know that the private information of agent $i$ is ' $x_{i}=1$ '. If on the other hand agent $i$ bids were $\$ 0.70$ for both ' 1 ' and ' 0 ' bit values, knowing that agent $i$ bid $\$ 0.70$ would not reveal agent $i$ 's private information bit value to another agent. In effect, if agents do not express relevant information, their private information is hidden behind their bid.

Axiom 1 for the "proper information market" simply guarantees that any agent, trading with any group of other agents, will learn new information from the first round market price that

\footnotetext{
${ }^{6} x_{i}^{\prime}$ denotes the opposite bit value of $x_{i} \in\{0,1\}$.
} 
results. Given a group of $n$ agents trading in a "proper information market", a new market for any $m$ (where $m \leq n$ ) of these agents may be constructed, and trading will result in a first round market price that all $m$ traders will learn from (by axiom 1 ).

Consider $n$ agents trading in a proper information market where they all express relevant information. It will be shown that the first round market price results from a unique arrangement of information bits across agents. Because it is unique, all agents may observe the first round market price to learn the private information of all other agents. All agents then submit a fully informed bid, which results in the DCE at the end of round 2.

By way of justifying the uniqueness, assume agent $i$ sees another arrangement of information bits across other agents that lead to the same first round market price. Let agent $i$ compare two arrangements that lead to this same first round market price. Let agent $i$ remove all other agents that had the same information in both arrangements and therefore contributed the same bid in both arrangements. Agent $i$ is now left with two new arrangements that lead to a single new market price; simply because agent $i$ has removed the same bid amounts from each of the original arrangements. It is important to notice that when agent $i$ now compares the two new arrangements, other agents do not have the same information bit in each arrangement. Therefore agent $i$ may consider the new market price but will not know with certainty the information bit of another agent. In short, it learns no information from the first round market price of this new group of traders. This contradicts with axiom 1 which requires the agent to learn something from the first round price of any group of traders, so the assumption that there is more than one arrangement that leads to the first round market price of $n$ traders must be false. That is, in a "proper information market where all agents express relevant information" all agents will observe a first round market price, identify a unique arrangement of information bits that leads to it, and full information bids will establish the DCE in the second round. Thus "all agents express relevant information" is a sufficient condition for convergence to the DCE in a proper information market.

\subsubsection{Theorem 2 (Relevant information as necessary for DCE convergence)}

"All agents express relevant information" is a necessary condition for convergence to the direct communication equilibrium (DCE) in a proper information market.

Consider a proper information market in which the DCE has been attained. This means that all agents have full information. Assume that there is at least one bit that is not relevant information. Of these bits consider private information bit $x_{j}$ of agent $j$. Since $x_{j}$ is not relevant information, all agents submit a bid that does not depend of the value of $x_{j}$. In turn a price $p$ is formed (which is the simple average of all bids) that does not depend on the value of $x_{j}$. Price $p$ is information that all agents receive to update their next round bids. Now price $p$ is information that is basically stating that $x_{j}$ could probably be ' 1 ' or ' 0 '. In short, $p$ not stating with certainty the value of $x_{j}$ in effect places a modicum of doubt on the actual value of $x_{j}$. Therefore, all agents update their beliefs to a probable rather than a certain value of $x_{j}$. That is, $p$ has caused the value of $x_{j}$ to no longer be considered certain. In our terms, $p$ has caused all agents to unlearn the value of $x_{j}$. But this contradicts axiom 2, which does not allow this unlearning to occur at the full information stage. Therefore, it must the case that all agents express relevant information. Hence "all agents express relevant information" is a necessary condition for convergence to the DCE.

The next logical step towards generalization by constructing a proper information (prediction) market with multiple contracts shall now be taken.

\subsubsection{Theorem 3 (Proper information market equilibrium with $r$ stocks)}


A proper information market with $r$ stocks converges to a market equilibrium in which each stock attains its DCE when all agents express relevant information.

For simplicity, a market with $r$ stocks may be thought of as $r$ markets with one stock; whereby a trader participates in each of the $r$ markets. That trader has 1 bit of private information per market; thus it has $r$ bits of private information in total. In our model, the $k^{\text {th }}$ bit of private information represents all the information required by the agent to inform their first round bid on the $k^{\text {th }}$ stock. All agents express relevant information about the $k^{\text {th }}$ stock and by theorem 1 the DCE for the $k^{\text {th }}$ stock is attained. In this way all stocks reach their respective DCE and the market of $r$ stocks has reached equilibrium.

Our proper information market with $r$ stocks is now used to build a simple decision market model. In order to do so, a variation to the payout structure of the contracts is made and the implications of this explored.

\subsubsection{Theorem 4 (Derivative attains DCE)}

A derivative on a stock attains its DCE in a proper information market "where all agents express relevant information".

A derivative in a stock market is in the most general sense a stock whose payout is dependent on another underlying stock. This derivative idea is used to create conditional probabilities; which are the bedrock of decision theory and our decision market. In our simplistic model some stock $k$ is called a derivative if it pays $\$ \mathrm{w}$ when stock $j$ pays $\$ 1$. In our market it may be shown that derivatives reach their DCE. Let all agents express relevant information in a proper information market. Firstly, notice that theorems 1 and 2 hold independent of currency used and that a $\$ \mathrm{w}$ payout is simply a $\mathfrak{Q} 1$ payout using some other currency denominated in $\mathfrak{L}$. Every agent will reason that "the probability of payout of the derivative given private information about that derivative" must be equal to "the probability of payout of the underlying stock given private information about that underlying stock". In essence, derivative stock $k$ appears identical to underlying stock $j$ in the first round with the exception that it is denominated in a different currency. Since theorems 1 and 2 do not depend on currency denomination and given stock $j$ converges to the DCE denominated in $\$$, the derivative stock $k$ is equivalent to stock $j$ converging to the DCE denominated in $\mathfrak{R}$. Say the derivative stock converges to a DCE of $\mathfrak{R} p$. Since $\mathfrak{R} 1$ may be exchanged for $\mathbb{\$} w$, the derivative's DCE is $\$ p \times w$.

\subsubsection{Theorem 5 (Probability derivative)}

For the DCE market price of derivative $k$ (e.g. \$0.70) to directly reflect the probability of $k$ being paid (e.g. 0.70), it requires a payout equal to "the market price of $k$ divided by the market price of underlying stock $j$ ", in a proper information market where all agents express relevant information. This type of derivative $k$ is called a probability derivative because it is a derivative with a market price that directly reflects the probability of it being paid.

When underlying stock $j$ has a DCE market price of say $\$ p=\$ 0.60$, this means that the probability of the event associated with stock $j$ is $p=0.60$. It is said that the market price $\$ p$ directly reflects the probability $p$ of stock $j$ being paid. It is also said that the market price $\$ p$ directly reflects the probability $p$ of the event associated with stock $j$ occurring. Say the payout of derivative $k$ is $\$ w$, then by theorem 4 it will reach a DCE market price of $\$ p \times w$. Let the probability of the event associated with stock $k$ be $q$. For the DCE market price of $k$ to directly reflect the probability $q$ of the associated event then it is required that $\$ p \times w=$ $\$ q$. This is rearranged to $w=\frac{q}{p}$. That is, a derivative payout equal to "the market price of $k$ divided by the market price of underlying stock $j$ " means that the DCE market price $\$ q$ of $k$ results when the probability of the event associated with $k$ is $q$. 


\subsubsection{Theorem 6 (Decision market contract payout structure)}

Consider a proper information market where all agents express relevant information and in which probability derivative $k$ (with DCE market price $\$ q$ ) is associated with the event "O and P occurs", and the underlying stock $j$ (with DCE market price $\$ p$ ) is associated with the event "P occurs". Then the derivative payout $(w)$ for $k$ represents "the conditional probability of $\mathrm{O}$ given $\mathrm{P}$ ".

Notice theorem 5 implies that the payout for $k$ is $w=\frac{q}{p}$. But this payout is simply "the probability that $\mathrm{O}$ and $\mathrm{P}$ occurs" divided by "the probability that $\mathrm{P}$ occurs"; which is "the conditional probability of O given P". For example, this may be used to express the probability of achieving some desired outcome $\mathrm{O}$ given project $\mathrm{P}$ is chosen.

With the previous example in mind, an organization may wish to choose the best project i.e. the project that when chosen maximizes the conditional probability of the desired outcome given the project. Theorem 7 provides a means to do this.

\subsubsection{Theorem 7 (Decision market selection rule)}

Consider a proper information market where all agents express relevant information and in which probability derivative $k_{v}$ (with DCE market price $\$ q_{v}$ ) is associated with the event "O and $P_{v}$ occurs", and the underlying stock $j_{v}$ (with DCE market price $\$ p_{v}$ ) is associated with the event " $P_{v}$ occurs"; the derivative payout for $k_{v}$ is represented by $w_{v}$. Consider a market filled with many such pairs of derivatives and underlying stock i.e. many different $v$ values. Then the pair with the highest derivative payout (say $w_{u}$ ) means that event $P_{u}$ maximizes the probability of event $\mathrm{O}$ occurring. $P_{u}$ is said to be the best.

Notice that theorem 6 implies that payout $\left(w_{v}\right)$ for $k_{v}$ represents "the conditional probability of O given $P_{v}$ ". In a decision theory setting the best $P_{v}$ is the one where "the conditional probability of $\mathrm{O}$ given $P_{v}$ " is of largest value. In this market, the derivative payout $w_{u}$ represents "the conditional probability of O given $P_{u}$ ". Since $w_{u}$ is the largest derivative payout it must be the case that that $P_{u}$ maximizes the probability of event $\mathrm{O}$ occurring. That is, $P_{u}$ is the best.

Notice that $P_{u}$ may represent the best project that a firm may wish to invest in to maximize their desired Outcome $(\mathrm{O})$ being achieved. The market in theorem 7 would select Project $P_{u}$. This market shall be called a simple decision market.

\section{Discussion}

Our strategy has been to develop a well-defined prediction market model from which to formulate a simple decision market. After reviewing relevant literature, a generally accepted prediction market model in Chen (2004) is modified to create our new prediction market model.

Our work employs an axiomatic approach to provide the rigor and transparency of mathematical formalism. Well-defined axioms are used to develop theorems that explore the dynamics of our information markets. Importantly, the sufficient and necessary condition for convergence to the direct communication equilibrium (DCE) in our new prediction market model is identified in theorems 1 and 2. Upon identifying this condition, it is enforced in our new prediction market models in theorems 3 to 7 . A payout and selection rule is defined, that links multiple contracts in our new prediction market model, to build a simple decision market model depicted in theorem 7 . Our investigation of the inherently more complex decision market setup is thus simplified by this modular approach. 
A key theoretical contribution of this paper is the logical introduction of axioms that ensure "agent learning" from first round market prices and prevent "agent unlearning" from last round market prices ${ }^{7}$. This is explored in section 4 of our work where the proper market price axioms are defined. Simply put, "axiom 1 prevents an agent from learning absolutely nothing from the first round market price (irrespective of the group or subgroup of market traders they participate with to generate that price)" and "axiom 2 prevents an agent with full information from unlearning information as a result of observing a market price". The proper market price axioms modify the prediction market model of Chen (2004) to form our new prediction market model. Importantly, our modification causes two mathematical properties to emerge that are central to our theorems. The new prediction market possessing these two properties is called "a proper information (prediction) market".

The proper information (prediction) market model setup provides the context to establish the sufficient and necessary conditions for convergence to the DCE. To this end relevant information is defined as an agent's information that, when changed, in turn changes the bid of that agent. Theorem 1 establishes that a sufficient condition for convergence to the DCE is that "all agents express relevant information" in a proper information market with one traded contract. Theorem 2 then shows that the condition "all agents express relevant information" is necessary for convergence to the DCE in a proper information market with one traded contract. Enforcing the sufficient and necessary "all agents express relevant information" condition in theorems 3 to 7 ensures that their proper information (prediction) markets are well behaved and converge to the DCE.

The construction of a prediction market model with multiple stock contracts was an important precursor to the development of a decision market; which inherently requires multiple stocks to express conditional probabilities. Theorem 3 provides a formal statement that guarantees convergence to the equilibrium in a prediction market with multiple agents who trade multiple stocks. It should be noted that agents enacting strategic behavior are not considered, thus the market equilibrium attained in theorem 3 is not strictly the rational expectations equilibrium; whereby rational expectations equilibrium has been defined as the market clearing price that does not cause strategically behaving agents to change their bid (Pennock and Sami, 2007). That is, the setup is simple and assumes rational, risk-neutral and myopic agents. There are two reasons for this. One, our idealized model can arguably still provide important insights about real world phenomenon as do other idealizations, e.g. the model of gravity without air resistance still provides a useful approximation to gravity dynamics near earth. Two, a game that is rational, risk-neutral and myopic incentive compatible rewards agents who play a dominant rational, risk-neutral and myopic strategy. In this way, the game arguably becomes a useful tool to efficiently aggregate distributed information and support decision making. Here the ultimate objective is not to model trader behavior in a real world market, rather, it is to accentuate trader behavior within a decision market game. This dichotomy is simply game theory versus inverse game theory. Whereby the former is interested in modeling player behavior given game rules, whereas the latter is interested in designing game rules to elicit specific player behavior; in our case revealing private information in a rational, risk-neutral and myopic decision market game (Chen and Pennock, 2010).

Further modification of contracts in our model led to a contract payout that was conditioned on another contract's payout. These new contracts with payouts that were dependent on an underlying stock being paid were called derivatives. Theorem 4 ensures that such derivatives converge to a DCE. From this point on, our new prediction market model in which "all agents express relevant information" about multiple contracts (be they stocks or derivatives) guarantees convergence of contracts to their respective DCE.

\footnotetext{
${ }^{7}$ By "last round market price" we mean the market price that is attained when all agents possess full information.
} 
Theorem 5 takes the key step towards a formal simple (joint elicitation type) decision market model. Whereas Theorem 4 constructs a derivative whose market price depends on the market price of the underlying stock, the market price of derivative does not necessarily directly convey the probability of the associated event occurring. It is theorem 5 that shows the necessary payout structure to ensure that the derivative market price also explicitly communicates the probability associated with the event that the derivative contract represents.

Theorem 6 builds upon theorem 5 and defines the exact setup of a market in which there are "project stocks" and "project \& outcome stocks" traded. What this paper calls projects, previous literature calls actions or decisions. Hence the best project, best decision, or best action have the same meaning here. Project applications are introduced in theorems 6 and 7 with a view to applying our decision market to a real world project selection setting in future work. The information market for theorem 7 acts to identify the (best) project that maximizes the likelihood of some desired outcome occurring. This information market is called a 'simple decision market'.

Theorems 6 and 7 show that the selection of the best project is consistent with the "project stock" paying $\$ 1$ if selected and the associated "project \& outcome stock" paying the derivative payout (which is simply the quotient of the "project \& outcome stock" market price and the "project stock" market price). The selection rule was simply that the "project and outcome stock" with the highest derivative payout should be selected.

Theorem 7 considers a market of many pairs of "project contract" and "project \& outcome contract". It formally shows that there exists a market of contract pairs, payouts and a selection rule that does indeed identify the best project. Theorem 7 models a group of agents that bid the expected values of "project contract" and "project \& outcome contract" across all market contracts. The same rational, risk-neutral and myopic agent behavior assumptions found in a popular theoretical market scoring rule decision market also holds in the market of theorem 7 (Chen et al., 2011). However, in contrast to that market scoring rule decision market, our simple decision market has a deterministic selection rule rather than a mixed strategy selection rule. That is, our decision market model has a $100 \%$ probability of selecting the best decision, whereas the market scoring rule decision market does not.

Our particular implementation of a decision market, described by Theorems 6 and 7, requires the payment of both the "outcome \& project" contract and the "project" contract at the same time. This contrasts with other decision market implementations found throughout literature whereby payment of some contracts is delayed to the observation of the outcome.

Specifically, in our model payment of the "outcome \& project" contract does not need to be delayed to the time at which the outcome is realized. This has implications in many real world contexts. For example, large investments have been made in projects that are long running and have a desired outcome considered over a long-term, e.g., mining projects, health programs, infrastructure investments, etc. For succinctness these shall be called "long-term outcome projects". Traders would arguably hesitate to participate in a decision market associated with a long-term outcome project where some contract payouts are delayed to the observation of the long term outcome. In such a decision market, the time-value-of-money considerations would certainly become pertinent and arguably invalidate the risk neutral assumption of the decision market model. Our decision market can arguably overcome this specific problem by simply running for a short time so that time effects become negligible. In short, our decision market may be run over a week prior to project selection and cease trading up until project selection. In this form, our decision market will be used to aggregate information for the firm to inform their project selection. It is important to note that this is not to say that the project selected by the decision market is the same as the project the firm 
selects ${ }^{8}$. However, it is likely that they are the same given that the decision market is arguably the best means to aggregate information for project selection purposes. In short, our simple decision market is simply a short running game that is used at the start of a project to inform real world decisions about project selection.

Our decision market model assumes rational, risk-neutral and myopic traders. In our model, Milgrom's no-trade possibility has been circumvented via forced trading. A simple forced trading rule can be easily introduced into the decision market game to ensure liquidity and revelation of private information. For example, a rule such as "each round a trader must submit an order quantity $q$ in the closed interval 0 to 100 , receive this quantity at the end of the round and pay $\frac{q}{2}$ cents" would guarantee trading and also ensure a trader bids the expected value of the contract conditioned on all information they have, as required in our decision market model.

What remains is extending our model to cater for contexts beyond a rational, risk-neutral and myopic setting. Our simple decision market model is populated by rational individual traders. However, it has been known for some time, that the rational trader assumption, in certain market settings, is false (Kahneman and Tversky, 1979). Our model confines itself to risk neutral traders. It has been suggested that the risk neutral agent assumption causes no loss of generality because of the mathematical equivalence between risk neutral and risk averse models (Chen et al., 2006). This suggestion arguably aligns with the equivalence seen in real options analysis (Cox et al., 1979). If true, this would make our findings more general, but to the best of our knowledge no such equivalence has as yet been rigorously proven for information markets. Our model also limits its scope to myopic traders. Hence the impact of strategic play begs analysis.

Despite the previously stated limitations of our simple decision market model, the central focus of this paper concerns whether relevant information is important for well-functioning decision markets. Our idealized decision market model and associated theorems clearly identify "relevant information" as important. As such, this theoretical finding compels further investigation of "relevant information" in laboratory and real world contexts. Specifically, is "relevant information" statistically significant in these contexts?

\section{Conclusion}

A simple decision market model of the joint elicitation type has been developed in this paper. A generally accepted prediction market model is modified to construct a simple decision market model. This modification provides original contributions to the theoretical discourse on information markets. Notably, the sufficient and necessary condition for convergence to the DCE in our new prediction market model is identified. Our new prediction market model contracts are then linked together whilst enforcing the sufficient and necessary condition for convergence in order to build a simple decision market model that is unencumbered by mixed strategy selection rules. Our work is made easy by our choice of mathematical formalism; a simple decision market nomenclature that is coherent, consistent and will continue to be utilized in our future work. Our simple decision market model inspires future work. Testing whether relevant information is statistically significant in a laboratory and real world decision markets follows logically from the model developed in this paper (which identifies relevant information as important).

${ }^{8}$ Traders are paid based on what the decision market selects, not what the firm selects. That is, traders simply play and are rewarded by the decision market game. 


\section{Appendix 1}

In this appendix the mathematical formalism on which our paper is based is provided. Importantly, detailed proofs build towards our simple decision market.

\section{Definition (direct communication equilibrium [DCE]):}

The market equilibrium reached when all agents have bids conditioned on full information $x$ (i.e. all agents bid $E[f(s) \mid x]$ ) shall be called the direct communication equilibrium (DCE). Notice that since the market price is the average of all bids then it is $E[f(s) \mid x]$.

\section{Axiom 1 and the private information stage property}

Axiom 1 is motivated by the notion that a trader will ideally learn something from the first round market price. Specifically, axiom 1 introduces into the model the idea that, irrespective of the participating traders, no first round market price is formed where an agent learns not a single piece of new information. That is, in our new model $\mathrm{w}$ any $m$ of the $n$ traders (where $m \leq n$ ) may be selected to form a first round market price that causes all of the $m$ traders to learn something new.

For example, consider these $m$ traders. They form a first round market price $p$. Arbitrarily chosen trader $i$ always knows its own private information bit $x_{i}$. Now, if trader $i$ learns no new piece of information from market price $p$ then it must believe that there are two ways to form this market price. Trader $i$ may consider that the market price was either formed by calculating $p=\frac{\sum b_{i}}{m}=\frac{\sum E\left[f(s) \mid x_{i}\right]}{m}=\frac{E\left[f(s) \mid x_{1}\right]+\cdots+E\left[f(s) \mid x_{i}\right]+\cdots+E\left[f(s) \mid x_{j}\right]+\cdots+E\left[f(s) \mid x_{m}\right]}{m}$, or formed by calculating

$p=\frac{\sum b_{i}}{m}=\frac{\sum E\left[f(s) \mid x_{i}\right]}{m}=\frac{E\left[f(s) \mid x_{1}\right]+\cdots+E\left[f(s) \mid x_{i}\right]+\cdots+E\left[f(s) \mid x_{j}\right]+\cdots+E\left[f(s) \mid x x^{\prime} m\right]}{m}$; where $x^{\prime}{ }_{j}$ denotes the opposite bit value of $x_{j}$ and all bit values except for $x_{i}$ are opposite bit values (e.g. for $k \neq i$, if $x_{k}=1$ in the first equation then $x^{\prime}{ }_{k}=0$ in the second equation).

Importantly, notice that agent $i$ does not know with certainty the information bit $x_{j}$ of any other agent $j$. That is, agent $i$ can only infer that market price $p$ resulted from either

(i) A market in which the bit value was $x_{j}$ where

$$
p=\frac{E\left[f(s) \mid x_{1}\right]+\cdots+E\left[f(s) \mid x_{i}\right]+\cdots+E\left[f(s) \mid x_{j}\right]+\cdots+E\left[f(s) \mid x_{m}\right]}{m} \text {, or }
$$

(ii) A market in which the bit value was $x_{j}^{\prime}$ where

$$
p=\frac{E\left[f(s) \mid x_{1}{ }_{1}\right]+\cdots+E\left[f(s) \mid x_{i}\right]+\cdots+E\left[f(s) \mid x^{\prime} j\right]+\cdots+E\left[f(s) \mid x_{m}^{\prime}\right]}{m} \text {. }
$$

Combine (i) and (ii) to form

$$
\begin{aligned}
& \frac{E\left[f(s) \mid x_{1}\right]+\cdots+E\left[f(s) \mid x_{i}\right]+\cdots+E\left[f(s) \mid x_{j}\right]+\cdots+E\left[f(s) \mid x_{m}\right]}{m}= \\
& \frac{E\left[f(s) \mid x_{1}{ }_{1}\right]+\cdots+E\left[f(s) \mid x_{i}\right]+\cdots+E\left[f(s) \mid x_{j}\right]+\cdots+E\left[f(s) \mid x_{m} m\right]}{m} .
\end{aligned}
$$

Simplify this further to form the equation

$$
\begin{aligned}
& E\left[f(s) \mid x_{1}\right]+\cdots+E\left[f(s) \mid x_{j}\right]+\cdots+E\left[f(s) \mid x_{m}\right] \\
= & E\left[f(s) \mid x_{1}^{\prime}\right]+\cdots+E\left[f(s) \mid x^{\prime}{ }_{j}\right]+\cdots+E\left[f(s) \mid x^{\prime}{ }_{m}\right]
\end{aligned}
$$

Or more concisely write:

$\sum_{k \neq i}^{m-1} E\left[f(s) \mid x_{k}\right]=\sum_{k \neq i}^{m-1} E\left[f(s) \mid x^{\prime}{ }_{k}\right]$ 
Notice that this equation signifies that agent $i$ only knows its private information bit $x_{i}$ and cannot infer with certainty some other agent's information bit from the first round market price. This would contravene axiom 1.

Axiom 1 requires that arbitrary agent $i$ learns something from the first round market price when trading with any group of traders. So it must be the case that the following property holds:

Private information stage property: For any agent $i, \sum_{k \neq i}^{m-1} E\left[f(s) \mid x_{k}\right] \neq \sum_{k \neq i}^{m-1} E\left[f(s) \mid x^{\prime}{ }_{k}\right]$ for all $m \leq n$, when at the private information stage.

\section{Axiom 2 and the full information stage property}

Axiom 2 is motivated by the notion that when all traders learn (know with certainty) all private information bit values at the full information stage, the market price cannot cause any trader to unlearn this full information $x=\left(x_{j}, x_{-j}\right)$. This implies that, at the full information stage, agent $i$ (where $i \neq j$ ) cannot observe a market price $p=E\left[f(s) \mid x_{-j}\right]$. If they did observe this, they would not know the private information bit value of agent $j$ with certainty; since $p=E\left[f(s) \mid x_{-j}\right]=P\left[x_{j} \mid x_{-j}\right] \times E\left[f(s) \mid x_{j}, x_{-j}\right]+P\left[x^{\prime}{ }_{j} \mid x_{-j}\right] \times E\left[f(s) \mid x^{\prime}{ }_{j}, x_{-j}\right]$ where $P\left[x_{j} \mid x_{-j}\right] \in(0,1)$. In effect observing market price $p=E\left[f(s) \mid x_{-j}\right]$ causes agent $i$ to unlearn $x_{j}$ when at the full information state (since $x_{j}$ is not known with certainty since $\left.P\left[x_{j} \mid x_{-j}\right] \in(0,1)\right)$. This would contravene axiom 2 .

It is trivial to show:

$$
p=E\left[f(s) \mid x_{j}, x_{-j}\right]=E\left[f(s) \mid x^{\prime}{ }_{j}, x_{-j}\right] \Rightarrow p=E\left[f(s) \mid x_{-j}\right]
$$

and

$p=E\left[f(s) \mid x_{j}, x_{-j}\right] \neq E\left[f(s) \mid x^{\prime}{ }_{j}, x_{-j}\right] \Rightarrow p=E\left[f(s) \mid x_{j}, x_{-j}\right] \neq E\left[f(s) \mid x_{-j}\right]$ where $P\left[x_{j}, x_{-j}\right], P\left[x^{\prime}{ }_{j}, x_{-j}\right], P\left[x_{-j}\right] \in(0,1)$.

Thus, for our purposes it is sufficient to require that the following property holds:

Full information stage property: Market prices at this stage must be such that $p=$ $E\left[f(s) \mid x_{j}, x_{-j}\right] \neq E\left[f(s) \mid x_{j}^{\prime}, x_{-j}\right]$ in order that the information bit value of agent $j$ is certainly known to some other agent $i$.

\section{Definition (proper market price):}

If a market price possesses both the "private information stage property" and the "full information stage property" it shall be called a proper market price.

\section{Definition (proper information market):}

Chen's prediction market model modified to require a proper market price, shall be called a proper information market.

\section{Definition (relevant information):}

The following lemmas provide a formal definition of relevant information.

Lemma 1.1 (relevant information): If agent $i$ bids $b_{i}=E\left[f(s) \mid x_{i}\right]=E\left[f(s) \mid x^{\prime}{ }_{i}\right]$ this is the same as if they bid $b_{i}=E[f(s)]$ and it is said that " $x_{i}$ is not relevant information and agent $i$ does not express a relevant information in their bid". Otherwise it is said " $x_{i}$ is relevant information and agent $i$ expresses relevant information in their bid".

Proof:

Given $E\left[f(s) \mid x_{i}\right]=E\left[f(s) \mid x^{\prime}{ }_{i}\right]$ 
This means $P\left[f \mid x_{i}\right]=P\left[f \mid x^{\prime}{ }_{i}\right]$ where $f$ is " $f(s)=1 "$.

By Bayes' law $\frac{P\left[x_{i} \mid f\right] P[f]}{P\left[x_{i}\right]}=\frac{P\left[x^{\prime} \mid f\right] P[f]}{P\left[x_{i}\right]}$.

And simplifying $P\left[x_{i} f\right] P\left[x_{i}^{\prime}\right]=P\left[x_{i}^{\prime} f\right] P\left[x_{i}\right]$.

Simplifying further to obtain $P\left[x_{i} f\right]=P[f] P\left[x_{i}\right]$,

Rearrange to obtain $E\left[f(s) \mid x_{i}\right]=E[f(s)]$ as required.

Lemma 1.2 (relevant information in general): Agent $i$ bidding such that $b_{i}=E\left[f(s) \mid x_{j}, Y\right]=E\left[f(s) \mid x_{j}^{\prime}, Y\right]$ is the same as if they bid $b_{i}=E[f(s) \mid Y]$ and it is said that " $x_{j}$ is not relevant information and agent $i$ does not express this relevant information in their bid". Otherwise it is said " $x_{j}$ is relevant information and agent $i$ expresses this relevant information in their bid".

Proof:

Given $b_{i}=E\left[f(s) \mid x_{j}, Y\right]=E\left[f(s) \mid x_{j}^{\prime}, Y\right]$

This means $P\left[f \mid x_{j}, Y\right]=P\left[f \mid x_{j}^{\prime}, Y\right]$ where $f$ is " $f(s)=1 "$

By Bayes' law $\left.\frac{P\left[x_{j}, Y \mid f\right] P[f]}{P\left[x_{j}, Y\right]}=\frac{P\left[x_{j}, Y \mid f\right] P[f]}{P\left[x_{j}, Y\right]}\right]$

And simplifying $P\left[x_{j} f Y\right] P\left[x_{j}^{\prime} Y\right]=P\left[x_{j}^{\prime} f Y\right] P\left[x_{j} Y\right]$

Simplifying further to obtain $P\left[x_{j} f Y\right] P[Y]=P[f Y] P\left[x_{j} Y\right]$

Rearrange to obtain $b_{i}=E\left[f(s) \mid x_{j} Y\right]=E[f(s) \mid Y]$ as required.

\section{Main information market theorems}

The main theorems for our new prediction market model are now presented and ultimately show that a simple decision market may be established using it.

Theorem 1 (Relevant information as sufficient for DCE convergence):

"All agents express relevant information" is a sufficient condition for convergence to the direct communication equilibrium (DCE) in a proper information market.

Proof:

Given "all agents express relevant information" in a proper information market.

At the end of the first round the market price will be revealed and is

$p=\frac{E\left[f(s) \mid x_{1}\right]+\cdots+E\left[f(s) \mid x_{n}\right]}{n}$. Any agent $i$ may consider all possible information vectors that attained $p$ and form a set which contains them

$X=\left\{a \in B^{n} \mid p=\frac{E\left[f(s) \mid a_{1}\right]+\cdots+E\left[f(s) \mid a_{n}\right]}{n}\right\}$ where $B=\{0,1\}$. Agent $i$ may reason that $X$ is not empty as it at the very least contains the actual information vector $x$ which was responsible for $p$. Agent $i$ may also reason that $X$ is a singleton set containing only $x$ via the following argument:

Agent $i$ assumes that some other information vector $\boldsymbol{y}$ leads to $\boldsymbol{p}$ where $y \in X$ and $y \neq x$. They may write $p=\frac{E\left[f(s) \mid x_{1}\right]+\cdots+E\left[f(s) \mid x_{n}\right]}{n}=\frac{E\left[f(s) \mid y_{1}\right]+\cdots+E\left[f(s) \mid y_{n}\right]}{n}$. This may be simplified to $E\left[f(s) \mid x_{1}\right]+\cdots+E\left[f(s) \mid x_{n}\right]=E\left[f(s) \mid y_{1}\right]+\cdots+E\left[f(s) \mid y_{n}\right]$. Since $x_{j}, y_{j} \in\{0,1\}$ we may "replace $y_{j}$ in the last equation with $x_{j}$ if $y_{j}=x_{j}$ " or "replace $y_{j}$ in the last equation with $x_{j}^{\prime}$ if $y_{j} \neq x_{j}$ " where $x_{j}^{\prime}$ denotes the opposite bit value of $x_{j}$. For example: $E\left[f(s) \mid x_{1}\right]+$ $E\left[f(s) \mid x_{2}\right]+E\left[f(s) \mid x_{3}\right]+\cdots+E\left[f(s) \mid x_{n}\right]=E\left[f(s) \mid x_{1}\right]+E\left[f(s) \mid x_{2}^{\prime}\right]+E\left[f(s) \mid x_{3}\right]+$ $\cdots+E\left[f(s) \mid x_{n}^{\prime}\right]$. Simplifying further and eliminate from both sides of the equation identical terms e.g. $E\left[f(s) \mid x_{1}\right]$ is eliminated from both sides but $E\left[f(s) \mid x_{2}\right]$ and $E\left[f(s) \mid x_{2}^{\prime}\right]$ remain given the relevant information assumption. Hence after simplification there is at least one term on both sides that are different and in general there are $l$ terms that remain on both sides since $y \neq x$. That is, we either have $E\left[f(s) \mid x_{k}\right]=E\left[f(s) \mid x^{\prime}{ }_{k}\right]$ or $\sum^{l} E\left[f(s) \mid x_{k}\right]=$ $\sum^{l} E\left[f(s) \mid x^{\prime}{ }_{k}\right]$ where $k \neq i$. However since "all agents express relevant information" this 
means $E\left[f(s) \mid x_{k}\right]=E\left[f(s) \mid x^{\prime}{ }_{k}\right]$ is not allowed by Lemma 1.1. Furthermore since the proper market price private information stage property holds $\sum^{m-1} E\left[f(s) \mid x_{k}\right] \neq \sum^{m-1} E\left[f(s) \mid x_{k}^{\prime}\right]$ for all $m \leq n$. Which implies the contradiction $\sum^{l} E\left[f(s) \mid x_{k}\right] \neq \sum^{l} E\left[f(s) \mid x^{\prime}{ }_{k}\right]$. Therefore it must be the case that "there does not exist some other information vector $y$ leading to p".

Thus, agent $i$ finds only information vector $x$ leads to the first round price $p$. Hence in round 2 all agents submit the bid $E[f(s) \mid x]$ which is exactly the direct communication equilibrium.

The 'necessary' condition proof shall now be considered.

Theorem 2 (Relevant information as necessary for DCE convergence):

"All agents express relevant information" is a necessary condition for convergence to the direct communication equilibrium (DCE) in a proper information market.

Proof:

Given the market has attained the direct communication equilibrium in a proper information market, all agents know all private information in the market $x=\left(x_{j}, x_{-j}\right)$ and the market is said to be at the full information stage.

\section{Assume that there exists at least one piece of information that is not relevant.}

This assumption at the very least implies the case where a single bit of information $x_{j}$ is not relevant.

Any arbitrarily chosen agent $i$ will bid such that $b_{i}=E\left[f(s) \mid x_{j}, x_{-j}\right]=E\left[f(s) \mid x_{j}^{\prime}, x_{-j}\right]=E\left[f(s) \mid x_{-j}\right]$ by lemma 1.2.

This means that the market price formed will be $p=\frac{\sum^{n} E\left[f(s) \mid x_{-j}\right]}{n}=E\left[f(s) \mid x_{-j}\right]$

But since, $E\left[f(s) \mid x_{j}, x_{-j}\right]=E\left[f(s) \mid x_{j}^{\prime}, x_{-j}\right]=E\left[f(s) \mid x_{-j}\right]$, then $p=E\left[f(s) \mid x_{j}, x_{-j}\right]=E\left[f(s) \mid x^{\prime}{ }_{j}, x_{-j}\right]$.

This contradicts the proper market price full information stage property whereby market prices at this stage must be such that $p=E\left[f(s) \mid x_{j}, x_{-j}\right] \neq E\left[f(s) \mid x_{j}^{\prime}, x_{-j}\right]$ in order that the information bit value of agent $j$ is certainly known to some other agent $i$.

In short, the assumption implies a market price that causes 'unlearning' of $x_{j}$ at the full information stage in contravention to axiom 2.

Therefore it must be the case that "All agents express relevant information".

The next logical step is now taken to construct a proper information (prediction) market with multiple contracts. Specifically, the convergence of this multi-stock model towards the direct communication equilibrium is of interest. Theorem 3 is a formal statement of such a model.

\section{Definition (Proper information market with $\mathbf{r}$ stocks):}

Suppose $r$ stocks are traded in a proper information market. The arbitrarily chosen $k^{\text {th }}$ stock is traded in a proper information market and represented by $F^{(k)} . F^{(k)}$ pays $\$ 1$ when the 
function $f^{(k)}(s)=1$ and pays $\$ 0$ otherwise; where $B=\{0,1\}$ and $s \in B^{N}$ is our usual representation of the state of the world with commonly know probability distribution $P(s)$. Assume that arbitrarily chosen agent $i$, in the first round bid, expresses its 1 bit of relevant information $x_{i}^{(k)}$ pertaining to the value of $f^{(k)}(s)$. Uncertainty of agents' information is commonly known in probability distribution $Q\left(x^{(k)} \mid s\right)$ where $x^{(k)} \in B^{n}$ and $n$ is the number of agents trading in the market. The collection of all $r$ stocks traded in this way shall be called a proper information market with $r$ stocks.

\section{Theorem 3 (Proper information market equilibrium with $\mathbf{r}$ stocks):}

A proper information market with $r$ stocks converges to a market equilibrium in which each stock attains its DCE when all agents express relevant information.

\section{Proof:}

Given a proper information market with $\mathrm{r}$ stocks denote $x_{i}^{(k)}$ as private information of arbitrarily chosen agent $i$ for the arbitrarily chosen $\mathrm{k}^{\text {th }}$ stock. "All agents express relevant information" is a necessary and sufficient condition for convergence to the DCE of a stock by previous theorems 1 and 2 . Therefore, the price of contract $F^{(k)}$ converges to DCE $E\left[f^{(k)}(s) \mid x^{(k)}\right]$. Since $\mathrm{k}$ is arbitrary, all $\mathrm{r}$ stocks converge to their respective direct communication equilibrium and hence the entire market reaches equilibrium.

\section{Simple Decision Market Model}

Our proper information market with $r$ stocks is used to build a simple decision market model. In order to do so, a variation to the payout structure of the contracts is considered.

Definition (t-contract): A stock contract $\mathrm{F}^{(\mathrm{k})}$ that pays $\$ \mathrm{t}$ when $\mathrm{f}^{(\mathrm{k})}(\mathrm{s})=1$ and pays $\$ 0$ when $\mathrm{f}^{(\mathrm{k})}(\mathrm{s})=0$ we shall call a $\mathrm{t}$-contract.

Lemma 4.1 (convergence of t-contracts): A t-contract converges to the DCE $\mathrm{E}\left[\mathrm{f}^{(\mathrm{k})}(\mathrm{s}) \mid \mathrm{x}^{(k)}\right] \mathrm{t}$ in a proper information market where "all agents express relevant information".

Proof: Consider a t-contract $\mathrm{F}^{(\mathrm{k})}$. Then it pays $\$ \mathrm{t}$ when $\mathrm{f}^{(\mathrm{k})}(\mathrm{s})=1$ and pays $\$ 0$ when $\mathrm{f}^{(\mathrm{k})}(\mathrm{s})=0$. The currency $(\$)$ could easily be exchanged for some other currency $(\varphi)$ where $\$ \mathrm{t}=\varphi 1$. Hence, consider $\mathrm{F}^{(\mathrm{k})}$ as paying $\varphi 1$ when $\mathrm{f}^{(\mathrm{k})}(\mathrm{s})=1$ and paying $\varphi 0$ when $\mathrm{f}^{(\mathrm{k})}(\mathrm{s})=$ 0 . This is the usual 1-contract that has been considered in the previous theorems. Given "all agents express relevant information", it converges to the DCE $\varphi E\left[f^{(k)}(s) \mid \mathrm{x}^{(k)}\right]$ by previous theorems. Since $\$ \mathrm{t}=\varphi 1$, the $\mathrm{t}$ contract converges to the DCE $\$ E\left[f^{(k)}(s) \mid \mathrm{x}^{(k)}\right] t$

Definition (Derivative): Given two contracts $\mathrm{F}^{(\mathrm{k})}$ and $\mathrm{F}^{(\mathrm{J})}$. It is said that $\mathrm{F}^{(\mathrm{k})}$ is a derivative of $\mathrm{F}^{(\mathrm{J})}$, if payment of $\mathrm{F}^{(\mathrm{J})}$ causes payment of $\mathrm{F}^{(\mathrm{k})}$. Formally, this shall require $\operatorname{Pr}\left[\mathrm{f}^{(\mathrm{k})}(\mathrm{s})=\right.$ $\left.1 \mid \mathrm{x}_{i}^{(k)}\right]=\operatorname{Pr}\left[\mathrm{f}^{(\mathrm{J})}(\mathrm{s})=1 \mid \mathrm{x}_{i}^{(J)}\right]$ in the first round.

Theorem 4 (Derivative attains DCE): If $\mathrm{F}^{(\mathrm{k})}$ is a derivative of $\mathrm{F}^{(\mathrm{J})}$, with the former being a w-contract and the latter a 1-contract, then $\mathrm{F}^{(\mathrm{k})}$ converges to the DCE E[f $\left.{ }^{(\mathrm{J})}(\mathrm{s}) \mid \mathrm{x}^{(J)}\right] \times \mathrm{w}$ in a proper information market "where all agents express relevant information".

Proof: Consider the w-contract $\mathrm{F}^{(\mathrm{k})}$. Agent $i$ bids $\mathrm{b}_{i}^{(k)}(\mathrm{w}-$ contract $)=\operatorname{Pr}\left[\mathrm{f}^{(\mathrm{k})}(\mathrm{s})=1 \mid \mathrm{x}_{i}^{(k)}\right] \times \mathrm{w}$ in the first round.

But given $\mathrm{F}^{(\mathrm{k})}$ is a derivative of $\mathrm{F}^{(\mathrm{J})}$ then it must be the case that 
$\operatorname{Pr}\left[\mathrm{f}^{(\mathrm{k})}(\mathrm{s})=1 \mid \mathrm{x}_{i}^{(k)}\right]=\operatorname{Pr}\left[\mathrm{f}^{(\mathrm{J})}(\mathrm{s})=1 \mid \mathrm{x}_{i}^{(J)}\right]$

which means

$\mathrm{b}_{i}^{(k)}(\mathrm{w}-$ contract $)=\operatorname{Pr}\left[\mathrm{f}^{(\mathrm{J})}(\mathrm{s})=1 \mid \mathrm{x}_{i}^{(J)}\right] \times \mathrm{w}$

which is equivalent in form to a first round bid on w-contract in $\mathrm{F}^{(\mathrm{J})}$.

Since "all agents express relevant information" and by lemma $6.1, \mathrm{~F}^{(\mathrm{k})}$ converges to the DCE $\mathrm{E}\left[\mathrm{f}^{(J)}(\mathrm{s}) \mid \mathrm{x}^{(J)}\right] \times \mathrm{w}$.

Definition (Probability Derivative): If $\mathrm{F}^{(\mathrm{k})}$ is a derivative of $\mathrm{F}^{(\mathrm{J})}$ in a proper information market where all agents express relevant information and the DCE of $\mathrm{F}^{(\mathrm{k})}$, denoted by $\operatorname{price}\left(F^{(k)}\right)$, equals the probability $\operatorname{Pr}\left[\mathrm{f}^{(\mathrm{k})}(\mathrm{s})=1 \mid \mathrm{x}^{(k)}\right]$, it is said that $\mathrm{F}^{(\mathrm{k})}$ is a probability derivative.

Definition (Probability of payment $\phi_{t}\left(F^{(k)}\right)$ ): The probability as at round t, that $\mathrm{F}^{(\mathrm{k})}$ pays $\$ 1$ at some future point in time, is represented by $\phi_{\mathrm{t}}\left(\mathrm{F}^{(\mathrm{k})}\right)$. Notice that if $\mathrm{F}^{(\mathrm{k})}$ is either a 1contract or a probability derivative that $\phi_{\mathrm{t}}\left(\mathrm{F}^{(\mathrm{k})}\right)=\operatorname{price}\left(\mathrm{F}^{(\mathrm{k})}\right)$ at the DCE; that is the probability of the contract paying $\$ 1$ is directly reflected in the price of the contract.

Theorem 5 (Probability derivative w-contract requirement): If $\mathrm{F}^{(\mathrm{k})}$ is a derivative of $\mathrm{F}^{(\mathrm{J})}$, with the former being a w-contract and the latter a 1-contract, then $\mathrm{w}=\frac{\phi_{\mathrm{t}}\left(\mathrm{F}^{(\mathrm{k})}\right)}{\phi_{\mathrm{t}}\left(\mathrm{F}^{(\mathrm{J})}\right)}$ ensures $\mathrm{F}^{(\mathrm{k})}$ is a probability derivative in a proper information market where all agents express relevant information.

Proof: Consider the w-contract $\mathrm{F}^{(\mathrm{k})}$.

In the first round $(t=1)$ Agent $i$ observes $\phi_{t}\left(F^{(k)}\right)=\operatorname{Pr}\left[\mathrm{f}^{(\mathrm{k})}(\mathrm{s})=1 \mid \mathrm{x}_{i}^{(k)}\right]$ and $\phi_{t}\left(F^{(J)}\right)=\operatorname{Pr}\left[\mathrm{f}^{(\mathrm{J})}(\mathrm{s})=1 \mid \mathrm{x}_{i}^{(J)}\right]$

Therefore they believe that $w=\frac{\phi_{t}\left(F^{(k)}\right)}{\phi_{t}\left(F^{(J)}\right)}=\frac{\operatorname{Pr}\left[\mathrm{f}^{(\mathrm{k})}(\mathrm{s})=1 \mid \mathrm{x}_{i}^{(k)}\right]}{\operatorname{Pr}\left[\mathrm{f}^{(\mathrm{J})}(\mathrm{s})=1 \mid \mathrm{x}_{i}^{(J)}\right]}$.

Because w-contract $\mathrm{F}^{(\mathrm{k})}$ is also a derivative of $\mathrm{F}^{(\mathrm{J})}$, in the first round Agent $i$ bids

$$
\begin{aligned}
\mathrm{b}_{i}^{(k)}(\mathrm{w}-\text { contract })= & \operatorname{Pr}\left[\mathrm{f}^{(\mathrm{J})}(\mathrm{s})=1 \mid \mathrm{x}_{i}^{(J)}\right] \times \$ \mathrm{w} \\
& =\operatorname{Pr}\left[\mathrm{f}^{(\mathrm{J})}(\mathrm{s})=1 \mid \mathrm{x}_{i}^{(J)}\right] \times \frac{\operatorname{Pr}\left[\mathrm{f}^{(\mathrm{k})}(\mathrm{s})=1 \mid \mathrm{x}_{i}^{(k)}\right]}{\operatorname{Pr}\left[\mathrm{f}^{(J)}(\mathrm{s})=1 \mid \mathrm{x}_{i}^{(J)}\right]} \\
& =\operatorname{Pr}\left[\mathrm{f}^{(\mathrm{k})}(\mathrm{s})=1 \mid \mathrm{x}_{i}^{(k)}\right]
\end{aligned}
$$

This is the usual 1-contract considered previously. Because all agents express relevant information, the DCE is attained in the second round. Therefore, price $\left(F^{(k)}\right)$ equals the probability $\operatorname{Pr}\left[\mathrm{f}^{(\mathrm{k})}(\mathrm{s})=1 \mid \mathrm{x}^{(\mathrm{k})}\right]$ as required.

Comment 5.1: Notice at DCE $\phi_{t}\left(F^{(k)}\right)=\operatorname{Pr}\left[\mathrm{f}^{(\mathrm{k})}(\mathrm{s})=1 \mid \mathrm{x}^{(\mathrm{k})}\right]=\operatorname{price}\left(F^{(k)}\right)$ and $\phi_{t}\left(F^{(J)}\right)=\operatorname{Pr}\left[\mathrm{f}^{(\mathrm{J})}(\mathrm{s})=1 \mid \mathrm{x}^{(J)}\right]=\operatorname{price}\left(F^{(J)}\right)$ which implies $\mathrm{w}=\frac{\operatorname{price}\left(\mathrm{F}^{(\mathrm{k})}\right)}{\operatorname{price}\left(\mathrm{F}^{(\mathrm{J})}\right)}$. 
Definition (Decision market contract pairs): It is said " $\mathrm{F}^{(\mathrm{k})}$ on $\mathrm{F}^{(\mathrm{J})}$ is the decision market pair for $\mathrm{O}$ and $\mathrm{P}$ ", if $\mathrm{F}^{(\mathrm{k})}$ represents the event "O and $\mathrm{P}$ occurs", $\mathrm{F}^{(\mathrm{J})}$ represents the event "P occurs", and $\mathrm{F}^{(\mathrm{k})}$ is a probability derivative of the 1-contract $\mathrm{F}^{(\mathrm{J})}$

Theorem 6 (Decision market contract payout structure): Assume a proper information market where all agents express relevant information, and all market prices have attained their respective DCE. If $\mathrm{F}^{(\mathrm{k})}$ on $\mathrm{F}^{(\mathrm{J})}$ is the decision market pair for $\mathrm{O}$ and $\mathrm{P}$, then the quotient of the market price of $\mathrm{F}^{(\mathrm{k})}$ and the market price $\mathrm{F}^{(\mathrm{J})}$ is equal to "the probability of $\mathrm{O}$ conditional on $\mathrm{P}$ and full information (denoted simply as $\operatorname{Pr}[O \mid P])^{9, "}$, and $\mathrm{F}^{(\mathrm{k})}$ is a w-contract, where $\mathrm{w}=$ $\frac{\operatorname{price}\left(\mathrm{F}^{(\mathrm{k})}\right)}{\operatorname{price}\left(\mathrm{F}^{(\mathrm{I})}\right)}=\operatorname{Pr}[\mathrm{O} \mid \mathrm{P}]$.

Proof: by assumptions, at the DCE $\operatorname{Pr}\left[\mathrm{f}^{(\mathrm{k})}(\mathrm{s})=1 \mid \mathrm{x}^{(k)}\right]=\operatorname{Pr}[O P]$ and $\operatorname{Pr}\left[\mathrm{f}^{(\mathrm{J})}(\mathrm{s})=1 \mid \mathrm{x}^{(J)}\right]=\operatorname{Pr}[P]$

Since $\mathrm{F}^{(\mathrm{J})}$ is a 1-contract, $\operatorname{Pr}\left[\mathrm{f}^{(J)}(\mathrm{s})=1 \mid \mathrm{x}^{(J)}\right]=\operatorname{price}\left(\mathrm{F}^{(J)}\right)$.

Since $\mathrm{F}^{(\mathrm{k})}$ is a probability derivative, $\operatorname{Pr}\left[\mathrm{f}^{(\mathrm{k})}(\mathrm{s})=1 \mid \mathrm{x}^{(k)}\right]=\operatorname{price}\left(\mathrm{F}^{(k)}\right)$

Therefore, $\operatorname{Pr}[O \mid P]=\frac{\operatorname{Pr}[\mathrm{OP}]}{\operatorname{Pr}[P]}=\frac{\left.\operatorname{Pr}\left[\mathrm{f}^{(\mathrm{k})}(s)=1 \mid \mathrm{x}^{(k)}\right)\right]}{\operatorname{Pr}\left[\mathrm{f}^{(J)}(\mathrm{s})=1 \mid \mathrm{x}^{(J)}\right]}=\frac{\operatorname{price}\left(\mathrm{F}^{(k)}\right)}{\operatorname{price}\left(\mathrm{F}^{(J)}\right)}$

Furthermore, $\mathrm{w}=\frac{\operatorname{price}\left(\mathrm{F}^{(\mathrm{k})}\right)}{\operatorname{price}\left(\mathrm{F}^{(\mathrm{I})}\right)}$ by comment 5.1

Therefore, $w=\frac{\operatorname{price}\left(\mathrm{F}^{(k)}\right)}{\operatorname{price}\left(\mathrm{F}^{(J)}\right)}=\operatorname{Pr}[O \mid P]$, as required.

Theorem 7 (Decision market selection rule): Given a proper information market of $2 \mathrm{M}$ contracts where all agents express relevant information. Specifically, let y index the contract, namely $\mathrm{y}=1$, to ..., $\mathrm{M}$ and for each $\mathrm{y}$ let there be contracts $\mathrm{F}^{(\mathrm{ky})}$ and $\mathrm{F}^{(\mathrm{Jy})}$. Let $\mathrm{F}^{(\mathrm{ky})}$ on $\mathrm{F}^{(\mathrm{Jy})}$ be the decision market pair for $\mathrm{O}$ and $\mathrm{P}_{\mathrm{y}}$, where $\mathrm{F}^{(\mathrm{ky})}$ is a $\mathrm{w}_{\mathrm{y}}$-contract. Also let there exist a selection rule that ensures only contracts $\mathrm{F}^{\left(\mathrm{Ky}^{*}\right)}$ and $\mathrm{F}^{\left(\mathrm{Jy}^{*}\right)}$ are paid if they satisfy the condition $\mathrm{y}^{*}=\operatorname{argmax}_{\mathrm{y}}\left(\mathrm{w}_{\mathrm{y}}\right)$, then this market setup is guaranteed to select the best ${ }^{10} \mathrm{P}_{\mathrm{y}}$. This shall be called a decision market for $\mathrm{P}$ given $\mathrm{O} .{ }^{11}$

Proof: by theorem $6, w_{y}=\operatorname{Pr}\left[O \mid \mathrm{P}_{y}\right]$

By substitution of this into the given selection rule

$$
y^{*}=\operatorname{argmax}_{y}\left(\operatorname{Pr}\left[O \mid \mathrm{P}_{y}\right]\right)
$$

The best decision theoretic $\mathrm{P}_{\mathrm{y}}$ satisfies this equation (Othman and Sandholm, 2010). Therefore, the best $\mathrm{P}_{\mathrm{y}}$ is selected.

\footnotetext{
${ }^{9}$ Strictly the conditional probability should be denoted $\operatorname{Pr}\left[O \mid P, x^{(k)}, x^{(J)}\right]$ but for brevity and without loss of meaning, write $\operatorname{Pr}[O \mid P] . \operatorname{Pr}[O \mid P]$ and $\operatorname{Pr}[O \mid P]$ are similarly treated.

${ }^{10}$ Best $\mathrm{P}_{\mathrm{y}}$ is that $\mathrm{P}_{\mathrm{y}}$ that when selected maximizes the likelihood of $\mathrm{O}$.

${ }^{11}$ This decision market is applicable to selecting the "Project" (from amongst alternative projects) that provides the greatest likelihood of achieving a desired "Outcome".
} 


\section{References}

AUMANN, R. J. 1976. Agreeing to disagree. The annals of statistics, 1236-1239.

BERG, J. E. \& RIETZ, T. A. 2003. Prediction markets as decision support systems. Information Systems Frontiers, 5, 79-93.

CHEN, Y., CHU, C.-H. \& MULLEN, T. 2006. Predicting uncertain outcomes using information markets: trader behavior and information aggregation. New Mathematics and Natural Computation, 2, 281-297.

CHEN, Y., DIMITROV, S., SAMI, R., REEVES, D. M., PENNOCK, D. M., HANSON, R. D., FORTNOW, L. \& GONEN, R. 2010. Gaming prediction markets: Equilibrium strategies with a market maker. Algorithmica, 58, 930-969.

CHEN, Y., KASH, I., RUBERRY, M. \& SHNAYDER, V. 2011. Decision markets with good incentives. Internet and Network Economics. Springer.

CHEN, Y. \& KASH, I. A. Information elicitation for decision making. The 10th International Conference on Autonomous Agents and Multiagent SystemsVolume 1, 2011. International Foundation for Autonomous Agents and Multiagent Systems, 175-182.

CHEN, Y., KASH, I. A., RUBERRY, M. \& SHNAYDER, V. 2014. Eliciting predictions and recommendations for decision making. ACM Transactions on Economics and Computation, 2, 6.

CHEN, Y., MULLEN, T. \& CHU, C.-H. Theoretical investigation of prediction markets with aggregate uncertainty. In Proceedings of the Seventh International Conference on Electronic Commerce Research (ICECR-7, 2004. Citeseer.

CHEN, Y. \& PENNOCK, D. M. 2010. Designing markets for prediction. AI Magazine, 31, 42-52.

CHEN, Y., REEVES, D. M., PENNOCK, D. M., HANSON, R. D., FORTNOW, L. \& GONEN, R. 2007. Bluffing and strategic reticence in prediction markets. Internet and Network Economics. Springer.

COX, J. C., ROSS, S. A. \& RUBINSTEIN, M. 1979. Option pricing: A simplified approach. Journal of financial Economics, 7, 229-263.

FEIGENBAUM, J., FORTNOW, L., PENNOCK, D. M. \& SAMI, R. Computation in a distributed information market. Proceedings of the 4th ACM conference on Electronic commerce, 2003. ACM, 156-165.

GAO, X. A. \& CHEN, Y. 2010. An axiomatic characterization of continuousoutcome market makers. Internet and Network Economics. Springer.

HANSON, R. 2002. Logarithmic market scoring rules for modular combinatorial information aggregation. George Mason University.

HANSON, R. 2003. Combinatorial information market design. Information Systems Frontiers, 5, 107-119.

HANSON, R. 2012. LOGARITHMIC MARKETS CORING RULES FOR MODULAR COMBINATORIAL INFORMATION AGGREGATION. The Journal of Prediction Markets, 1, 3-15.

KAHNEMAN, D. \& TVERSKY, A. 1979. Prospect theory: An analysis of decision under risk. Econometrica: Journal of the Econometric Society, 263-291.

MCKELVEY, R. D. \& PAGE, T. 1986. Common knowledge, consensus, and aggregate information. Econometrica: Journal of the Econometric Society, 109-127.

MILGROM, P. \& STOKEY, N. 1982. Information, trade and common knowledge. Journal of Economic Theory, 26, 17-27. 
OTHMAN, A. \& SANDHOLM, T. Decision rules and decision markets. Proceedings of the 9th International Conference on Autonomous Agents and Multiagent Systems: volume 1-Volume 1, 2010. International Foundation for Autonomous Agents and Multiagent Systems, 625-632.

PENNOCK, D. M. \& SAMI, R. 2007. Computational aspects of prediction markets. Algorithmic game theory, 651-674.

RONEN, A. \& WAHRMANN, L. 2005. Prediction games. Internet and Network Economics. Springer.

SANDHOLM, T. W. Limitations of the Vickrey auction in computational multiagent systems. Proceedings of the Second International Conference on Multiagent Systems (ICMAS-96), 1996. 299-306.

SHAPLEY, L. \& SHUBIK, M. 1977. Trade using one commodity as a means of payment. The Journal of Political Economy, 937-968.

TZIRALIS, G. \& TATSIOPOULOS, I. 2012. Prediction markets: An extended literature review. The journal of prediction markets, 1, 75-91. 